\title{
Rethinking regenerative medicine: a macrophage-centered approach
}

\author{
Bryan N. Brown ${ }^{1,2 \dagger}$, Brian M. Sicari ${ }^{1,3 \dagger}$ and Stephen F. Badylak ${ }^{1,3 *}$ \\ ${ }^{1}$ McGowan Institute for Regenerative Medicine, University of Pittsburgh, Pittsburgh, PA, USA \\ ${ }^{2}$ Department of Bioengineering, University of Pittsburgh, Pittsburgh, PA, USA \\ ${ }^{3}$ Department of Surgery, University of Pittsburgh, Pittsburgh, PA, USA
}

\section{Edited by:}

Charles Dudley Mills, BioMedical

Consultants, USA

\section{Reviewed by:}

Fulvio D'Acquisto, Queen Mary

University of London, UK

Manuela Mengozzi, Brighton and

Sussex Medical School, UK

*Correspondence:

Stephen F. Badylak, McGowan Institute for Regenerative Medicine,

Suite 300, 450 Technology Drive,

Pittsburgh, PA 15219, USA

e-mail: badylaks@upmc.edu

${ }^{\dagger}$ Bryan N. Brown and Brian M. Sicari have contributed equally to this work.
Regenerative medicine, a multi-disciplinary approach that seeks to restore form and function to damaged or diseased tissues and organs, has evolved significantly during the past decade. By adapting and integrating fundamental knowledge from cell biology, polymer science, and engineering, coupled with an increasing understanding of the mechanisms which underlie the pathogenesis of specific diseases, regenerative medicine has the potential for innovative and transformative therapies for heretofore unmet medical needs. However, the translation of novel technologies from the benchtop to animal models and clinical settings is non-trivial and requires an understanding of the mechanisms by which the host will respond to these novel therapeutic approaches. The role of the innate immune system, especially the role of macrophages, in the host response to regenerative medicine based strategies has recently received considerable attention. Macrophage phenotype and function have been suggested as critical and determinant factors in downstream outcomes. The constructive and regulatory, and in fact essential, role of macrophages in positive outcomes represents a significant departure from the classical paradigms of host-biomaterial interactions, which typically consider activation of the host immune system as a detrimental event. It appears desirable that emerging regenerative medicine approaches should not only accommodate but also promote the involvement of the immune system to facilitate positive outcomes. Herein, we describe the current understanding of macrophage phenotype as it pertains to regenerative medicine and suggest that improvement of our understanding of context-dependent macrophage polarization will lead to concurrent improvement in outcomes.

Keywords: regenerative medicine, biomaterials, host response, foreign-body reaction, stem cells, macrophages

\section{INTRODUCTION}

The macrophage has long been known to play an important role in the tissue remodeling response which occurs following injury. In brief, macrophages arrive at the site of tissue injury $24-48 \mathrm{~h}$ postinjury, serve as phagocytes clearing the wound bed and initiating the processes that lead to the default outcome of scar tissue formation $(1,2)$. However, only recently it has been recognized that macrophages can have positive impacts upon tissue remodeling following injury (3-9). While the specific mechanisms by which macrophages direct tissue remodeling responses remain a subject of ongoing research, it has been suggested that a transition from a pro-inflammatory (M1) phenotype to a more regulatory or antiinflammatory M2 phenotype is a key aspect of tissue remodeling which promotes functional outcomes as opposed to scar tissue formation.

A correlation of macrophage phenotype with functional recovery in wound healing has been suggested for more than two decades (9). With the introduction and general acceptance of the M1/M2 phenotypic dichotomy (10), correlation of macrophage polarization states and functional recovery has now been reported in several other tissues and organ systems and represents an area of increasing interest for those in the area of wound healing and regeneration. The central dogma of this macrophage-centered approach is that treatments which facilitate an efficient and timely switch from a pro-inflammatory to an anti-inflammatory and regulatory phenotype, will logically promote functional tissue remodeling over scar tissue formation.

The M1/M2 paradigm has been widely studied in the context of disease pathogenesis, particularly cancer, for more than two decades (11-13). The participation of M1 and M2 macrophages in a diverse set of diseases including atherosclerosis, endometriosis, and pulmonary fibrosis is also now recognized $(2,12,14-18)$. In addition, there is evidence for the importance of macrophages in tissue and organ development and in processes such as limb regeneration in the axolotl $(19,20)$. Loss of macrophages during these processes leads to defects in development or retardation of the regenerative process in the axolotl. Similar findings have been reported in other regenerative species including zebrafish, where ablation of macrophages results in defects in fin regeneration following injury (21). This ability to promote a regenerative response is lost in higher order species with increasing complexity of the 
immune system, having been replaced with a default mechanism of "rapid resolution" (i.e., scarring). While the mechanisms which underlie the loss of regenerative potential remain largely unknown, a better understanding of the role of the innate immune system in the regenerative process of lower organisms may provide targets for regeneration strategies in humans (22).

Regenerative medicine approaches to tissue reconstruction or organ replacement seek to restore the form and function of lost, damaged, or diseased tissues. These approaches logically rely upon our understanding of wound healing, development, and regeneration as guideposts for design. These approaches may incorporate one or more biomaterials, biologically active molecules, and/or cell sources. Recent advances in these areas have enabled highly innovative and promising therapies, but translation of such strategies, without exception, requires in depth investigation and understanding of the host response following delivery.

The purpose of the present review is (1) to provide rationale for a macrophage centric approach to tissue reconstruction; and (2) to give an overview of the current state-of-the-understanding of the implications associated with host macrophage responses in regenerative medicine.

It should be noted that the description of macrophages as having either an M1 or M2 phenotype is a simplification of the in vivo reality. Though it is now clear that $\mathrm{M} 1$ and M2 macrophages each play distinct roles in tissue remodeling following injury, the inflammatory process which occurs following injury is dynamic both spatially and temporally and macrophages may express transitional phenotypes. Logically, these cells will also express functions such as phagocytosis, antigen presentation, and effector molecule production to differing degrees during the inflammation and remodeling process. For the purposes of simplicity and general discussion, and as the M1/M2 terminology are used ubiquitously throughout the literature, we describe macrophage phenotype as M1 and M2 in the below examples with further discussion of the spectrum of possible phenotypes and their potential roles in regenerative medicine thereafter.

\section{A MACROPHAGE CENTRIC APPROACH}

There is evidence for both pathogenic and protective roles of macrophages in many biologic processes $(12,23)$. It is well understood that uncontrolled inflammation can be a detrimental process (e.g., inflammatory bowel disease, rheumatoid arthritis). However, an organized and well regulated macrophage response has been shown to be a determinant of tissue remodeling following injury, with the potential for positive outcomes and functional recovery. The key role of macrophages in functional recovery following injury suggests that methods which are capable of modulating the macrophage response in a controlled, reproducible, and well-defined manner, may also meet with improved outcomes in regenerative medicine applications. Below, we review the role of macrophages in the response to tissue injury and the subsequent remodeling process in three different tissue environments as a baseline from which to understand the potential role of macrophages in regenerative medicine approaches to tissue reconstruction and to provide the rationale for a macrophage centric approach.

\section{THE M1/M2 PARADIGM DURING THE SKELETAL MUSCLE INJURY RESPONSE}

The role of the M1/M2 paradigm during the skeletal muscle injury response is relatively well characterized. Skeletal muscle tissue possesses inherent regenerative capacity following acute injury such as exercise-induced trauma. The capacity of muscle tissue to regenerate relies heavily upon a population of normally quiescent muscle specific progenitor cells, referred to as "satellite cells," and their interactions with inflammatory cells that infiltrate the injured muscle microenvironment $(24,25)$. An efficient skeletal muscle injury response which successfully restores the injured muscle tissue requires satellite cell progression through a structured process of activation including proliferation and subsequent maturation into committed myoblasts, myoblast alignment, and finally, fusion and differentiation into new contractile skeletal muscle myotubes (26-29). This carefully regulated process of satellite cell differentiation is controlled, in large part, by the activity of an orchestrated heterogeneous inflammatory response consisting predominantly of M1 and M2 polarized macrophages (30, 31).

Following acute skeletal muscle injury, one of the earliest events is the infiltration of the damaged tissue by inflammatory cells. Neutrophils comprise the initial wave of cells to enter the damaged muscle tissue and reach elevated levels as soon as $2 \mathrm{~h}$ post-injury and maximum numbers after 6-24h $(30,32,33)$. Neutrophils phagocytose host necrotic cellular or bacterial debris and propagate a pro-inflammatory response through the release of reactive oxygen species and T-helper (Th) 1 associated pro-inflammatory cytokines, which recruit monocytes and macrophages. However, neutrophil numbers decline through apoptosis and the neutrophil response is generally resolved by 3-4 days post-injury (30). Monocyte-derived macrophages recruited to the damaged tissue shortly after neutrophil infiltration represent the predominant immunologic participant in the skeletal muscle injury response thereafter.

Monocytes originate in the bone marrow and express chemokine receptors and adhesion molecules which facilitate their extravasation and migration from the blood to the injured skeletal muscle tissue site where they differentiate into macrophages $(34,35)$. Tissue resident macrophages normally found within the skeletal muscle microenvironment are also likely to play a role. However, the relative contributions of tissue resident macrophages as compared to circulating macrophages to the tissue remodeling process remain unknown. Immediately after injury, infiltrating macrophages become polarized toward a proinflammatory or M1 phenotype. The mechanisms behind this M1 activation remain only partially understood and include macrophage exposure to pro-inflammatory cytokines (i.e., IFN$\gamma$, TNF- $\alpha$ ) and/or necrotic cellular or bacterial debris (30, 35-37). M1 macrophages within the injured muscle microenvironment phagocytose necrotic muscle debris and participate in a transient pro-inflammatory response, reaching elevated levels at $24 \mathrm{~h}$ post-injury and maximum numbers after 2 days $(30,35)$. In addition to producing large amounts of pro-inflammatory cytokines (i.e., TNF- $\alpha$, IL-1 $\beta$, IL-12), M1 macrophages process and present antigen and express high levels of iNOS which facilitates NO production $(38,39)$. 
After 2 days, macrophages participating in the remodeling of injured skeletal muscle show a transition from the pro-inflammatory $\mathrm{M} 1$ to the immunoregulatory and antiinflammatory M2 phenotype. The mechanisms behind this M1 to M2 phenotypic switch remain only partially understood but include exposure of M1 macrophages to increased IL-10 concentrations from skeletal muscle at $48 \mathrm{~h}$ post-injury $(40,41)$; M1 macrophage mediated phagocytosis of apoptotic, as opposed to necrotic, cells $(40,42)$; and exposure of M1 macrophages to degradation products from extracellular matrix (ECM) (43). M2 macrophages reach peak numbers within areas of injured muscle at 4 days post-injury and remain a predominant cell-type present in the remodeling muscle microenvironment for several days $(44,45)$. M2 macrophages facilitate resolution of inflammation through the release of anti-inflammatory cytokines (i.e., IL-10, IL-13), which deactivate pro-inflammatory cell phenotypes and promote tissue remodeling and repair $(35,44,45)$.

This transition of the initial response dominated by $\mathrm{M} 1$ macrophages to a more M2 dominated population following acute muscle injury facilitates skeletal muscle remodeling and is required for efficient and compete functional restoration. Specifically, the pro-inflammatory products of M1 macrophages promote the activation and expansion of quiescent muscle satellite cells within the tissue injury site $(35,38,46,47)$. For example, TNF- $\alpha$ produced in large quantities by $\mathrm{M} 1$ macrophages represents a well-accepted mitogen for satellite cell-derived skeletal muscle myoblasts (31, 48). Following satellite cell and myoblast expansion, paracrine signals from M2 macrophages facilitate the alignment, fusion, and differentiation, of these skeletal muscle progenitor cells. For example, IL-10, an immunomodulatory cytokine produced by M2 macrophages, is myogenic for skeletal muscle progenitor cells (4, 31).

The participation of a heterogeneous population macrophages following muscle injury is highly regulated. For example, the perturbation or prolongation of either the M1 or M2 macrophage population during the skeletal muscle injury response results in impaired skeletal muscle regeneration. Depletion of phagocytic leukocytes, including macrophages, prior to toxin induced skeletal muscle injury blocks the removal of cellular debris and impairs regeneration (31). Depletion of macrophages at the time of injury prevents the participation of M1 macrophages in the early response and therefore shows their importance to muscle regeneration $(31,49)$. Furthermore, immediately following injury, skeletal muscle shows decreased activity of muscle specific transcription factors in TNF- $\alpha$ knockout animals when compared to their wild-type counterparts $(50,51)$, suggesting that TNF- $\alpha$ from M1 macrophages promotes the early or proliferative stage of myogenesis. However, prolonging TNF- $\alpha$ activity beyond the early proliferative stage of myogenesis has deleterious effects. While TNF- $\alpha$ promotes skeletal muscle precursor cell mitogenesis, it also inhibits myogenesis (52-54).

The participation of M2 macrophages is also required for the skeletal muscle injury response. As stated above, these immunomodulatory cells drive the late or differentiation stage of myogenesis. For example, when macrophages were deleted after 2 days post-injury, a time point consistent with the transition to an M2 macrophage response, myoblast differentiation, and subsequent regeneration was impaired (55). Furthermore, transgenic animals unable to mount a M2 macrophage response show an accumulation of proliferative myoblasts and a lack of myogenic differentiation following injury (7). These studies show the importance of a present, yet regulated, M1 to M2 phenotypic transition of macrophages for efficient skeletal muscle regeneration.

\section{THE M1/M2 PARADIGM DURING CUTANEOUS WOUND HEALING}

Adult mammalian cutaneous wound healing is another highly regulated process that follows a sequence of events comprising the following three interdependent and overlapping phases: (1) the inflammatory phase; (2) the granulation tissue formation and wound contraction phase; and (3) the matrix deposition and tissue remodeling phase $(56,57)$. Multiple studies have now demonstrated distinct macrophage phenotypes associated with each of these phases and with remodeling outcomes following injury.

The onset of wound healing, designated the inflammatory phase, can be further sub-divided into an early and late inflammatory phase. Immediately following injury, hemostasis provides a provisional matrix for cell migration. During the early inflammatory phase, which occurs at 1-4 days post-injury, neutrophils and monocyte-derived macrophages respond to pro-inflammatory signals released from the wound microenvironment including growth factors, cytokines, damage associated molecular patterns (DAMPS), and pathogen associated molecular patterns (PAMPS) (58). These pro-inflammatory effector molecules along with the presence of necrotic cellular and bacterial debris facilitate the polarization of infiltrating macrophages toward the M1 phenotype (59). M1 macrophages associated with the early inflammatory phase are highly phagocytic and participate in the inflammatory phase by producing large quantities of pro-inflammatory cytokines (i.e., TNF- $\alpha$ ), proteases, and ROS with the ultimate goal of pathogen control and removal of necrotic cell and tissue debris $(57,59)$.

The late inflammatory phase, which occurs at 5-7 days postinjury, is marked by an accumulation of apoptotic as opposed to necrotic cells, which upon phagocytosis facilitate the polarization of macrophages toward the immunomodulatory M2 phenotype (59). During the granulation tissue formation and wound contraction phase of cutaneous wound healing at 7-10 days post-injury, paracrine effector molecules, including cytokines such as IL-10 and growth factors such as VEGF, PDGF- $\beta$, and TGF- $\beta$, produced by M2 macrophages recruit fibroblasts into the wound site and promote myofibroblast differentiation $(6,60)$. M2 macrophages continue to release anti-inflammatory and pro-angiogenic factors, which facilitate the resolution of inflammation, recruitment of endothelial cells, and deposition of new $\operatorname{ECM}(61,62)$. Activated myofibroblasts bridge the wound gap and develop contractile forces to facilitate wound contraction. Growth factors produced by M2 macrophages and myofibroblasts synergistically promote the proliferation and migration of keratinocytes to facilitate wound re-epithelialization $(60,61)$.

The matrix deposition and tissue remodeling phase, which occurs after 10 days post-injury, is marked by a decrease in macrophage numbers populating the wound site, along with an overall decrease in total cellularity. Granulation tissue formation 
reaches a plateau and tissue present within the wound site is partially remodeled into fibrotic scar tissue at this time $(56,57)$.

The above stages of cutaneous wound healing are carefully regulated by the activity of responding macrophages. Similar to the M1/M2 macrophage paradigm associated with the skeletal muscle injury response, cutaneous wound healing is dependent upon a heterogeneous macrophage population and an M1 to M2 phenotypic transition. The pro-inflammatory activity of M1 macrophages during the early inflammatory phase is required for efficient pathogen control. Conversely, M2 macrophage activity during the late inflammatory phase is required for the resolution of inflammation and the recruitment of cells, which facilitate granulation tissue formation and wound re-epithelialization. Perturbation of the M1 macrophage phenotype during the early inflammatory phase, either by conditional depletion or due to impaired recruitment, results in delayed granulation tissue formation and wound closure $(63,64)$. Similarly, prolonging the M1 macrophage phenotype (i.e., preventing the phenotypic transition to M2) through the exogenous addition of TNF- $\alpha$ during the late inflammatory phase also resulted in poor wound remodeling outcomes (65). Depletion of M2 macrophages during the late inflammatory phase results in prolonged inflammation and impaired wound repair $(63,66)$. These M2 macrophage depleted cutaneous wounds resemble chronic wounds typically associated with the pathogenesis of chronic venous ulcers (CVU) and diabetes. In fact, studies have shown that failure of cutaneous wound macrophages to undergo the M1 to M2 phenotypic transition represents a hallmark of these chronic inflammatory diseases (65, 67, 68). Taken together, these studies show the importance of functional macrophage heterogeneity and the extent to which immunomodulatory effects of M2 macrophages are critical for efficient wound healing and tissue remodeling.

\section{THE M1/M2 PARADIGM DURING THE CNS INJURY RESPONSE}

The role of M1 and M2 macrophages following injury in the central nervous system (CNS) is more ambiguous when compared to other tissues, and is made more complex by the presence of the blood-brain barrier. However, similarities to the macrophage heterogeneity associated with the injury response in other tissues are increasingly being reported.

Central nervous system resident macrophages, referred to as microglia, have long been considered the primary responders to injury in the CNS with little to no role having been recognized for circulating cells until recently. Generally, microglia are recruited to, and form a dense barrier around, the lesion site immediately following spinal cord injury $(69,70)$. These activated microglia produce large quantities of cytotoxic factors and proinflammatory cytokines including IL- $1 \beta$, IL- 6 , and TNF- $\alpha$. This pro-inflammatory response facilitates pathogen control and debris clearance, and also the recruitment of neutrophils and bloodderived monocytes and macrophages (5, 71-73); however, this response is also commonly cited as a driver of poor remodeling outcomes following injury in the CNS. As with other tissue injury responses, functional remodeling following CNS injury involves a transition from a pro-inflammatory to an immunoregulatory and homeostatic response. It remains unknown if microglia show M1 to M2 phenotypic plasticity similar to that observed to monocyte-derived macrophages. However, recent studies suggest that CNS microglia drive an early pro-inflammatory response, but infiltrating macrophages from the circulation may facilitate the M2-like tissue remodeling response (74). Specifically, recruited blood-derived macrophages, showing an anti-inflammatory phenotype consistent with M2 polarization, do not directly enter the lesion center, but are found around the lesion site at 3 days postinjury $(74,75)$. These immunoregulatory macrophages have been shown to arrive at the site of injury by specifically trafficking through a remote blood-cerebrospinal-fluid (CSF) barrier, the brain ventricular choroid plexus (CP) (8). Once at the injury site, these M2 macrophages produce IL-10 for mitigation of the pro-inflammatory response and contribute to repair mechanisms including remyelination $(8,75,76)$.

The participation of M2 polarized macrophages in the CNS injury response is essential to the repair process. For example, the endogenous partial recovery which can be observed following spinal cord injury is abrogated when M2-like macrophages are depleted using antibodies or conditional ablation (74, 75). Consistent with this notion, blockage of CP mediated macrophage trafficking inhibits M2 macrophage recruitment and subsequently impaired recovery following injury (76). These studies show the importance of a heterogeneous macrophage response to CNS injury and, specifically, that M2 macrophages contribute to processes beyond inflammation.

The above studies support an emerging dogma of effective recovery from tissue injury in which initial responses consisting predominantly of M1 macrophages and secondary or later stages consisting predominantly of M2 macrophages drive functional remodeling outcomes. Furthermore, it is appears that M2 macrophages contribute to more than immunomodulation during the response which follows tissue injury. Several organ systems, in addition to the above examples of muscle, skin, and CNS tissue have now been shown to undergo similar responses following injury and are also characterized by heterogeneous and temporally shifting macrophage phenotypes.

\section{A DEPARTURE FROM THE "CLASSICAL PARADIGM"}

The observation of dichotomies in macrophage phenotype in disease pathogenesis as well as tissue remodeling following injury represents a departure from the classical understanding of the macrophage as a primarily phagocytic and pro-inflammatory cell. The foreign-body reaction (FBR) has been well studied over the last three decades (77). Logically, this response is an extension of normal wound healing as the implantation of a biomaterial necessarily requires the creation of a surgical injury. The seminal works in this area by Anderson $(77,78)$ and others describe the host response to implanted materials as occurring in stages including injury (implantation), protein adsorption, acute inflammation, chronic inflammation, FBR, granulation tissue formation, and encapsulation. These processes are well recognized to be dominated by mononuclear cells, and macrophages in particular.

During a FBR persistent inflammatory stimuli, such as the presence of a non-degradable biomaterial, lead to chronic inflammation and the formation of multinucleated foreign-body giant cells (79). Multinucleate giant cells are formed by the fusion of persistent pro-inflammatory macrophages, consistent with the M1 
phenotype, located at the surface of the biomaterial and further exacerbate the deleterious inflammatory response through a process known as "frustrated phagocytosis" $(80,81)$. Failure to resolve the inflammatory response results in a FBR, leading to the deposition of disorganized fibrous tissue consistent with scaring and encapsulation of the implant $(82,83)$. This dense fibrous scar isolates the implant and prevents its integration with the surrounding host tissue.

The interpretation of the FBR as a negative occurrence in this context led to the development of materials with a focus on "inertness" and "biocompatibility" (84-86). This focus upon the host response to biomaterials resulted in an associated emphasis upon the material characteristics which determine the host response and downstream outcomes. However, these same characteristics may not be ideal in the setting of regenerative medicine where the focus is upon the restoration of function through the development of new host tissues rather than through the provision of a simple mechanical substitute. These concepts do not imply that medical devices such as hip implants and surgical mesh are not effective for their intended functions, but rather that the intended use, and therefore, the design characteristics and functional requirements, of these materials are incompatible with the goals of regenerative medicine.

The emergence of regenerative medicine and the need and desire for therapies which restore endogenous tissue function has led to a significant increase in our understanding of the role of stem cells in tissue repair as well as innovation and development of new biomaterials as stand alone therapies and/or delivery systems for cells or biologic factors. These materials are most often degradable in nature, and include engineered biologic cues or inherent bioactivity when derived from natural or tissue based sources. As such, the host response to these materials will be significantly different and more complex than the response to mono-component, synthetic or metallic implants. Further complexity is seen when materials are used in combination with cells or other factors.

It is now recognized that certain materials when used alone or in concert with a cellular component can provide an inductive template for constructive and functional tissue remodeling. That is, the provision of a bioactive material and/or cells leads to the formation of new, site-appropriate tissue. One example of such materials is biologic scaffolds composed of ECM $(87,88)$. These materials are derived through the decellularization of source tissues and organs and are widely utilized in regenerative medicine approaches to tissue reconstruction $(89,90)$. By the nature of the source (i.e., intact tissue), the materials that result from efficient decellularization can be thought of as degradable reservoirs of tissue specific structural and functional components. These materials have been shown to be effective templates for constructive remodeling in both pre-clinical and clinical applications, and in several body systems $(87,88)$. However, it should be noted that reports of the effectiveness of ECM based scaffold materials are variable and highly dependent on the methods of scaffold production.

Despite the distinct differences in long-term outcomes which have been observed with various ECM based scaffold materials, all ECM implants have been shown to elicit a histologically similar cellular response in the first week to month post-implantation $(3,91)$. This response is characterized by an early infiltrate of neutrophils followed by a dense infiltrate of mononuclear cells. Under the classical paradigm, such a response would commonly be associated with progression to a FBR with negative implications for functional tissue remodeling outcomes. However, the response typically proceeds down one of three distinct pathways: (1) a classic FBR with encapsulation and no signs of constructive remodeling; (2) chronic inflammation and degradation or integration of the material with little to no constructive remodeling; or (3) reduction of the inflammatory infiltrate with subsequent constructive remodeling $(3,91)$.

Based upon these disparate outcomes, it was hypothesized that, though the early host response to the materials was histologically similar (i.e., characterized by a dense infiltration of mononuclear cells in the site of implantation), differences in the early macrophage phenotype to certain ECM scaffold materials might exist and that these differences may be related to downstream remodeling outcomes. Indeed, this hypothesis was shown to be correct with those ECM scaffolds which elicited constructive remodeling outcomes being associated with a timely transition from an M1 to an M2 macrophage phenotype (3, 92, 93). These studies have provided the impetus for investigation of macrophage phenotype in a number of regenerative medicine applications using biomaterials and cell-based therapies. The results of these investigations now clearly show a correlation between macrophage phenotype and successful outcomes associated with multiple regenerative medicine strategies. A review of selected studies which demonstrate this phenomenon are described below with a focus upon multiple strategies (materials, cells, and bioactive factors) which show associations between macrophage phenotype and remodeling outcomes.

\section{THE M1/M2 PARADIGM IN TISSUE ENGINEERING AND REGENERATIVE MEDICINE}

An endogenous host injury response, consisting of immunomodulation, including the participation of M2 type macrophages represents a necessary component of efficient and functional tissue repair. It is therefore logical that regenerative medicine strategies aimed at activating or augmenting endogenous repair mechanisms should utilize a similar strategy. Regenerative medicine strategies aimed at promoting M2 macrophage activation have included celltherapy and the implementation of synthetic and biologic scaffold materials, among others.

\section{CELLULAR THERAPY}

Cellular therapy is generically defined as the transplantation or delivery of exogenous cells to sites of injured or missing tissues. Stem and/or progenitor cells are often used in regenerative medicine applications because of their multi-lineage differentiation potential and well-recognized resistance to oxidative stress $(94,95)$.

The cell source is most commonly autologous due to immune rejection considerations, although many studies are investigating the use of allogeneic sources. Cellular therapy based strategies aimed at promoting tissue remodeling have been used to treat injured tissues including the myocardium, the spinal cord, and skeletal muscle, among others. Despite moderate pre-clinical and clinical success, cell-therapy is associated with limitations 
including failure of the exogenous cells to engraft within host tissue (96-101). It is now increasingly recognized that therapeutic outcomes associated with cellular therapy are largely a result of paracrine effects exerted by the transplanted or delivered cells upon the injured host tissue microenvironment rather than direct differentiation of the transplanted cells into new tissues (102-107). These paracrine effects include modulation of macrophage polarization and beneficial remodeling events facilitated by a transition to the M2 macrophage phenotype (108-110).

Co-culture experiments have shown that the secreted products of different stem/progenitor cells directly promote an M2 macrophage phenotype (111-113). A large number of pre-clinical studies also support these results. For example, following spinal cord injury, transplanted bone marrow-derived mesenchymal stem cells (MSC) modulate the host inflammatory microenvironment by promoting an M1 to M2 transition, which ultimately leads to a permissive environment for axonal extension and functional recovery (114). Furthermore, following traumatic brain injury, intravenous (IV) delivery of multipotent progenitor cells promotes the polarization of microglia to an M2-like phenotype (115). Several studies, using cells of multiple origins (i.e., autologous and allogeneic bone marrow-derived MSCs, adipose derived MSCs, and umbilical derived MSCs, among others), suggest that the therapeutic effects associated with exogenous cell delivery for the treatment of myocardial infarction are a result of enhanced macrophage polarization switching (116118). Cellular therapy mediated M2 macrophage polarization has been used to promote tissue remodeling and repair in several anatomic locations and disease states including kidney ischemiareperfusion injury and asthma associated alveolar inflammation, among others (119-121).

\section{SCAFFOLD MATERIALS}

Regenerative medicine strategies aimed at promoting tissue reconstruction or replacement often employ the use of surgically implantable synthetic or biologic materials designed to serve as cellular support scaffolds. As described above, implantation of these materials following injury alters the default injury response. For example, following surgical placement, synthetic and/or biologic scaffold materials are able to affect the phenotype of infiltrating inflammatory cells, host progenitor cell activity, as well as fibrosis and fibrous capsule development $(78,122)$. These effects depend on the scaffold composition, degradability, cellularity, porosity, and implantation site among others (78).

\section{SYNTHETIC SCAFFOLD MATERIALS}

As stated above, the surgical placement of non-degradable synthetic scaffold materials is commonly associated with a FBR consisting of persistent M1 macrophage activity and an increased deposition of scar tissue $(3,78,91,123-125)$. Recently, strategies aimed at modulating material properties to reduce the persistent pro-inflammatory M1 macrophage response to synthetic biomaterials have been examined. These strategies have included alterations in scaffold surface chemistry and structural characteristics. However, some of the studies examining these strategies are associated with conflicting results. For example, one study suggests that synthetic scaffold materials composed of fibers with smaller diameters are associated with more M2-like macrophage activation when compared to their larger diameter counterparts (126). In contrast, another study showed that larger fiber diameter enhanced M2 macrophage polarization (127).

A recent series of studies has demonstrated the effects of material pore size upon integration of the material as well as macrophage phenotype $(13,128-131)$. In these studies, materials were produced with tight distributions of pore sizes. Results showed that materials possessing pores of roughly $30-40 \mu \mathrm{m}$ were shown to integrate with reduced encapsulation and higher vascularity when implanted into dermis or cardiac tissues $(13,131)$. These changes in outcome were also associated with shifts in macrophage phenotype $(128,131)$. However, interestingly, the shifts in phenotype were observed to be spatially distinct with cells outside of the pore templated implants having an increased M2 phenotype as compared to non-porous implants, and the cells within the implant having a predominantly M1 phenotype (128). These studies suggest that manipulation of the structural and surface characteristics of synthetic scaffold materials can affect macrophage phenotype. Specifically, some of these manipulations appear to alter the macrophage response and are also associated with improved outcomes.

Another manner in which biomaterials can be tailored to promote shifts in macrophage phenotype is through the use of biologically active molecules such as growth factors and cytokines. Examples of these approaches are numerous and are commonly employed in regenerative medicine with resulting improvements in remodeling outcomes. A recent study investigated the effects of incorporation of either M1 (IFN- $\gamma$ ) or an M2 (IL-4) promoting cytokines within a polysulfone tube upon nerve growth across a gap defect when the tubes were used as guidance conduits (132). The results of the study demonstrated that polarization of macrophages toward a more M2 phenotype was associated with increased Schwann cell infiltration and neurite outgrowth. These effects were further examined in vitro, with results suggesting that macrophage derived factors were at least in part the cause of the observed chemotaxis of Schwann cells.

\section{BIOLOGIC SCAFFOLD MATERIALS}

The biologically derived scaffold materials used in regenerative medicine applications are sourced from a variety of natural sources including mammalian tissues as well as plant, insect, and bacterial sources. These materials offer the inherent advantage of the native ligand landscape and bioactivity resulting from their source material. This inherent bioactivity also leads to added complexity in the host response to these materials. Among these materials, scaffolds derived from mammalian tissues represent the most commonly used materials in pre-clinical and clinical regenerative medicine applications (133-135).

Biologic scaffold materials composed of mammalian ECM have been used to promote constructive tissue remodeling in a variety of clinical applications including hernia repair, rotator cuff reconstruction, esophageal preservation, and skeletal muscle replacement, among others $(88,136,137)$. ECM bioscaffolds are derived through the decellularization of mammalian tissue $(89,90,138)$. The most common tissue sources are xeno- or allogeneic in nature 
and include decellularized dermis, small intestine, bladder, and pericardium among others.

It is now well recognized that the ability of these materials to promote constructive remodeling is tied to their ability to modulate the host macrophage response $(3,92,93,135)$. Multiple studies have shown that ECM based scaffold materials which are properly prepared facilitate a transition from an M1 to an M2 phenotype around $7-14$ days post-implantation $(3,92,93)$. The exact mechanisms by which these materials facilitate this response remain largely unknown; however, a number of key aspects have been identified. The materials must be adequately decellularized to remove potentially immunogenic cellular constituents and the material must be able to degrade $(3,92,93,139)$. In the presence of excess cellular material or if the material has been chemically crosslinked to prevent degradation, an extended M1 type immune response with no transition to an M2 response is observed and is associated with poor remodeling outcomes or encapsulation.

The necessity of degradation for the transition to an M2 phenotype suggests that breakdown products of the ECM scaffold material may possess immunomodulatory activity. Studies have shown that ECM bioscaffolds can be solubilized and the degradation products formed into a hydrogel under physiologic conditions $(140,141)$. This hydrogel ECM, when used as a coating for polypropylene surgical mesh, can facilitate a transition from the default M1 and FBR type response to a more M2 type response with a reduction in the FBR and encapsulation (142). These results, as well as other recent in vitro studies, further demonstrate the inherent immunomodulatory nature of ECM based biomaterials as well as their ability to improve remodeling outcomes $(124,142)$.

\section{WORDS OF CAUTION}

The above examples clearly illustrate an emerging paradigm in regenerative medicine. That is, strategies which are able to modulate the host response from an M1 to an M2 macrophage response are associated with better outcomes. However, these results should be interpreted with caution. Macrophage phenotypes have been described in many ways (143). "M1" and "M2" (with M2 macrophages including subsets M2a, M2b, and M2c) represents the common terminology used to describe these cells. Macrophage phenotypes have also been described as a spectrum between M1 and M2 with any individual cell being capable of expressing multiple aspects of either phenotype at any given time. Given this phenotypic heterogeneity, and the transient nature of the remodeling process following injury, further study of biomaterials-macrophage and stem cell-macrophage interactions are warranted, as is more thorough definition of the resultant phenotypes and their unique functions. It is unlikely that macrophages which result from interactions with biomaterials, particularly those with inherent naturally occurring ligand landscapes, or stem cells will possess phenotypes which precisely resemble the canonical IFN- $\gamma$ and LPS (M1) or IL-4, IL-13 (M2a), IC and TLR/IL1-R ligand (M2b), or IL-10 (M2c) activated macrophages.

Adding further complexity to the definition of macrophage phenotypes in regenerative medicine applications is the variability in tissue resident macrophage populations. For example, microglia are the resident macrophages of the brain and derive from the embryonic yolk sac during development and persist in the brain thereafter, presumably through a process of local replication (144146). As is described above, these cells have been demonstrated in a number of studies to have phenotypes which are distinct from circulating monocyte-derived macrophages and are known to play distinct roles in a number of CNS disease processes. Other tissue resident macrophage populations also exist, each with a distinct and tissue specific phenotype (147). While a full description of tissue resident macrophages in all body systems and their distinct phenotypic characteristics is beyond the scope of this review, it is important to understand how these differences and the relative contributions of local versus circulating cells will affect outcomes.

At present, studies investigating macrophage phenotype following exposure to biomaterial implants have largely relied upon single surface or gene expression markers as indicators of M1 and M2 polarization. It is now well established that macrophages possess highly complex and plastic phenotypes and that the use of multiple phenotypic markers is essential. Further, a better understanding of the functional implications of these phenotypes is needed to create a mechanistic understanding of the ways in which macrophages may direct tissue remodeling outcomes following biomaterial implantation or stem cell delivery. With this understanding, next generation therapies can be developed to target and modulate specific macrophage phenotypes with desirable characteristics for the given application.

It should further be recognized that baseline macrophage polarization states may be affected by patient characteristics. As is mentioned above, there is now increasing evidence for changes in macrophage phenotype and response to activating stimuli with age and disease both acute and chronic $(12,23,148,149)$. Commonly employed pharmacologic interventions may also affect the response. Also, it is logical that the tissue microenvironment which results following an injury may also be different than that which is experimentally and sterilely created in an animal model. Thus, there is a need to investigate macrophage response to regenerative medicine strategies in animal models which, at least in part, can mimic aspects of these complex situations.

\section{CONCLUSION}

Macrophage polarization has been clearly shown to be an important determinant of success in regenerative medicine strategies for tissue reconstruction. Macrophages can promote both positive and negative outcomes, which are dependent upon the context in which they are encountered, their phenotype, and function. However, at present, there remains much to be investigated and defined regarding macrophage phenotypes associated with biomaterials, stem cells, and regenerative medicine. Thus, context specific definitions and identification of beneficial phenotypes are needed. Similarly, the unique functions of these cells must also be clearly defined in order to better understand their true role in the remodeling process. Indeed, a focus upon macrophage function during the process of constructive remodeling may prove more useful than further characterization of complex phenotypic markers. Moving studies from correlative to causative and expanding the number of outcome metrics, both phenotypic and functional, will assist in defining both biomaterials and stem cell associated phenotypes and also provides targets for next generation regenerative medicine therapies, which seek to modulate macrophages as a 
means of promoting functional tissue recovery - a macrophage centric approach. It is increasingly clear that those strategies that adopt such an approach to regenerative medicine will meet with improved success.

\section{REFERENCES}

1. Adamson R. Role of macrophages in normal wound healing: an overview. J Wound Care (2009) 18(8):349-51. doi:10.12968/jowc.2009.18.8.43636

2. Koh TJ, DiPietro LA. Inflammation and wound healing: the role of the macrophage. Expert Rev Mol Med (2011) 13:e23. doi:10.1017/S1462399411001943

3. Brown BN, Londono R, Tottey S, Zhang L, Kukla KA, Wolf MT, et al. Macrophage phenotype as a predictor of constructive remodeling following the implantation of biologically derived surgical mesh materials. Acta Biomater (2012) 8(3):978-87. doi:10.1016/j.actbio.2011.11.031

4. Deng B, Wehling-Henricks M, Villalta SA, Wang Y, Tidball JG. IL-10 triggers changes in macrophage phenotype that promote muscle growth and regeneration. J Immunol (2012) 189(7):3669-80. doi:10.4049/jimmunol.1103180

5. Longbrake EE, Lai W, Ankeny DP, Popovich PG. Characterization and modeling of monocyte-derived macrophages after spinal cord injury. J Neurochem (2007) 102(4):1083-94. doi:10.1111/j.1471-4159.2007.04617.x

6. Novak ML, Koh TJ. Macrophage phenotypes during tissue repair. J Leukoc Biol (2013) 93(6):875-81. doi:10.1189/jlb.1012512

7. Ruffell D, Mourkioti F, Gambardella A, Kirstetter P, Lopez RG, Rosenthal $\mathrm{N}$, et al. A CREB-C/EBPbeta cascade induces M2 macrophage-specific gene expression and promotes muscle injury repair. Proc Natl Acad Sci U S A (2009) 106(41):17475-80. doi:10.1073/pnas.0908641106

8. Shechter R, Miller O, Yovel G, Rosenzweig N, London A, Ruckh J, et al. Recruitment of beneficial M2 macrophages to injured spinal cord is orchestrated by remote brain choroid plexus. Immunity (2013) 38(3):555-69. doi:10.1016/j. immuni.2013.02.012

9. Albina JE, Mills CD, Henry WL Jr, Caldwell MD. Temporal expression of different pathways of 1-arginine metabolism in healing wounds. J Immunol (1990) 144(10):3877-80.

10. Mills CD, Kincaid K, Alt JM, Heilman MJ, Hill AM. M-1/M-2 macrophages and the Th1/Th2 paradigm. J Immunol (2000) 164(12):6166-73. doi:10.4049/ jimmunol.164.12.6166

11. Mantovani A, Sozzani S, Locati M, Allavena P, Sica A. Macrophage polarization: tumor-associated macrophages as a paradigm for polarized M2 mononuclear phagocytes. Trends Immunol (2002) 23(11):549-55. doi:10.1016/S14714906(02)02302-5

12. Mills CD. M1 and M2 macrophages: oracles of health and disease. Crit Rev Immunol (2012) 32(6):463-88. doi:10.1615/CritRevImmunol.v32.i6.10

13. Mills CD, Shearer J, Evans R, Caldwell MD. Macrophage arginine metabolism and the inhibition or stimulation of cancer. J Immunol (1992) 149(8):2709-14.

14. Brown BN, Ratner BD, Goodman SB, Amar S, Badylak SF. Macrophage polarization: an opportunity for improved outcomes in biomaterials and regenerative medicine. Biomaterials (2012) 33(15):3792-802. doi:10.1016/j. biomaterials.2012.02.034

15. Capobianco A, Rovere-Querini P. Endometriosis, a disease of the macrophage. Front Immunol (2013) 4:9. doi:10.3389/fimmu.2013.00009

16. Pechkovsky DV, Prasse A, Kollert F, Engel KM, Dentler J, Luttmann W, et al. Alternatively activated alveolar macrophages in pulmonary fibrosismediator production and intracellular signal transduction. Clin Immunol (2010) 137(1):89-101. doi:10.1016/j.clim.2010.06.017

17. Smith KA, Pearson CB, Hachey AM, Xia DL, Wachtman LM. Alternative activation of macrophages in rhesus macaques (Macaca mulatta) with endometriosis. Comp Med (2012) 62(4):303-10.

18. Stoger JL, Gijbels MJ, van der Velden S, Manca M, van der Loos CM, Biessen EA, et al. Distribution of macrophage polarization markers in human atherosclerosis. Atherosclerosis (2012) 225(2):461-8. doi:10.1016/j.atherosclerosis.2012. 09.013

19. Pollard JW. Trophic macrophages in development and disease. Nat Rev Immunol (2009) 9(4):259-70. doi:10.1038/nri2528

20. Godwin JW, Pinto AR, Rosenthal NA. Macrophages are required for adult salamander limb regeneration. Proc Natl Acad Sci U S A (2013) 110(23):9415-20. doi:10.1073/pnas.1300290110
21. Li L, Yan B, Shi YQ, Zhang WQ, Wen ZL. Live imaging reveals differing roles of macrophages and neutrophils during zebrafish tail fin regeneration. J Biol Chem (2012) 287(30):25353-60. doi:10.1074/jbc.M112.349126

22. Godwin JW, Rosenthal N. Scar-free wound healing and regeneration in amphibians: immunological influences on regenerative success. Differentiation (2014) 87(1-2):66-75. doi:10.1016/j.diff.2014.02.002

23. Wynn TA, Chawla A, Pollard JW. Macrophage biology in development, homeostasis and disease. Nature (2013) 496(7446):445-55. doi:10.1038/nature12034

24. Mauro A. Satellite cell of skeletal muscle fibers. J Biophys Biochem Cytol (1961) 9:493-5. doi:10.1083/jcb.9.2.493

25. Muir AR, Kanji AH, Allbrook D. The structure of the satellite cells in skeletal muscle. J Anat (1965) 99(Pt 3):435-44.

26. Wozniak AC, Kong J, Bock E, Pilipowicz O, Anderson JE. Signaling satellite-cell activation in skeletal muscle: markers, models, stretch, and potential alternate pathways. Muscle Nerve (2005) 31(3):283-300. doi:10.1002/mus.20263

27. Zammit PS, Partridge TA, Yablonka-Reuveni Z. The skeletal muscle satellite cell: the stem cell that came in from the cold. J Histochem Cytochem (2006) 54(11):1177-91. doi:10.1369/jhc.6R6995.2006

28. Hawke TJ, Garry DJ. Myogenic satellite cells: physiology to molecular biology. J Appl Physiol (2001) 91(2):534-51.

29. Charge SB, Rudnicki MA. Cellular and molecular regulation of muscle regeneration. Physiol Rev (2004) 84(1):209-38. doi:10.1152/physrev.00019.2003

30. Tidball JG, Villalta SA. Regulatory interactions between muscle and the immune system during muscle regeneration. Am J Physiol Regul Integr Comp Physiol (2010) 298(5):R1173-87. doi:10.1152/ajpregu.00735.2009

31. Arnold L, Henry A, Poron F, Baba-Amer Y, van Rooijen N, Plonquet A, et al. Inflammatory monocytes recruited after skeletal muscle injury switch into antiinflammatory macrophages to support myogenesis. J Exp Med (2007) 204(5):1057-69. doi:10.1084/jem.20070075

32. Bondesen BA, Mills ST, Pavlath GK. The COX-2 pathway regulates growth of atrophied muscle via multiple mechanisms. Am J Physiol Cell Physiol (2006) 290(6):C1651-9. doi:10.1152/ajpcell.00518.2005

33. Contreras-Shannon V, Ochoa O, Reyes-Reyna SM, Sun D, Michalek JE, Kuziel WA, et al. Fat accumulation with altered inflammation and regeneration in skeletal muscle of CCR2-/- mice following ischemic injury. Am J Physiol Cell Physiol (2007) 292(2):C953-67. doi:10.1152/ajpcell.00154.2006

34. Swirski FK, Nahrendorf M, Etzrodt M, Wildgruber M, Cortez-Retamozo V, Panizzi P, et al. Identification of splenic reservoir monocytes and their deployment to inflammatory sites. Science (2009) 325(5940):612-6. doi:10.1126/ science. 1175202

35. Tidball JG. Inflammatory processes in muscle injury and repair. Am J Physiol Regul Integr Comp Physiol (2005) 288(2):R345-53. doi:10.1152/ajpregu.00454. 2004

36. St Pierre BA, Tidball JG. Differential response of macrophage subpopulations to soleus muscle reloading after rat hindlimb suspension. J Appl Physiol (1994) 77(1):290-7.

37. McLennan IS. Degenerating and regenerating skeletal muscles contain several subpopulations of macrophages with distinct spatial and temporal distributions. J Anat (1996) 188(Pt 1):17-28.

38. Villalta SA, Nguyen HX, Deng B, Gotoh T, Tidball JG. Shifts in macrophage phenotypes and macrophage competition for arginine metabolism affect the severity of muscle pathology in muscular dystrophy. Hum Mol Genet (2009) 18(3):482-96. doi:10.1093/hmg/ddn376

39. Gordon S, Taylor PR. Monocyte and macrophage heterogeneity. Nat Rev Immunol (2005) 5(12):953-64. doi:10.1038/nri1733

40. Cohen HB, Mosser DM. Extrinsic and intrinsic control of macrophage inflammatory responses. J Leukoc Biol (2013) 94(5):913-9. doi:10.1189/jlb. 0413236

41. Liu D, Sartor MA, Nader GA, Gutmann L, Treutelaar MK, Pistilli EE, et al. Skeletal muscle gene expression in response to resistance exercise: sex specific regulation. BMC Genomics (2010) 11:659. doi:10.1186/1471-2164-11-659

42. Fadok VA, Bratton DL, Konowal A, Freed PW, Westcott JY, Henson PM. Macrophages that have ingested apoptotic cells in vitro inhibit proinflammatory cytokine production through autocrine/paracrine mechanisms involving TGF-beta, PGE2, and PAF. J Clin Invest (1998) 101(4):890-8.

43. Sicari BM, Dziki JL, Siu BF, Medberry CJ, Dearth CL, Badylak SF. The promotion of a constructive macrophage phenotype by solubilized extracellular matrix. Biomaterials (2014) 35(30):8605-12. doi:10.1016/j.biomaterials.2014. 06.060 
44. Gordon S, Martinez FO. Alternative activation of macrophages: mechanism and functions. Immunity (2010) 32(5):593-604. doi:10.1016/j.immuni.2010. 05.007

45. Gordon S. Alternative activation of macrophages. Nat Rev Immunol (2003) 3(1):23-35. doi:10.1038/nri978

46. Collins RA, Grounds MD. The role of tumor necrosis factor-alpha (TNFalpha) in skeletal muscle regeneration. Studies in TNF-alpha(-/-) and TNFalpha(-/-)/LT-alpha(-/-) mice. J Histochem Cytochem (2001) 49(8):989-1001. doi:10.1177/002215540104900807

47. Zador E, Mendler L, Takacs V, de Bleecker J, Wuytack F. Regenerating soleus and extensor digitorum longus muscles of the rat show elevated levels of TNF-alpha and its receptors, TNFR-60 and TNFR-80. Muscle Nerve (2001) 24(8):1058-67. doi:10.1002/mus. 110

48. Li YP. TNF-alpha is a mitogen in skeletal muscle. Am J Physiol Cell Physiol (2003) 285(2):C370-6. doi:10.1152/ajpcell.00453.2002

49. Teixeira CF, Zamuner SR, Zuliani JP, Fernandes CM, Cruz-Hofling MA, Fernandes I, et al. Neutrophils do not contribute to local tissue damage, but play a key role in skeletal muscle regeneration, in mice injected with Bothrops asper snake venom. Muscle Nerve (2003) 28(4):449-59. doi:10.1002/mus.10453

50. Chen SE, Gerken E, Zhang Y, Zhan M, Mohan RK, Li AS, et al. Role of TNF\{alpha\} signaling in regeneration of cardiotoxin-injured muscle. Am J Physiol Cell Physiol (2005) 289(5):C1179-87. doi:10.1152/ajpcell.00062.2005

51. Warren GL, Hulderman T, Jensen N, McKinstry M, Mishra M, Luster MI, et al. Physiological role of tumor necrosis factor alpha in traumatic muscle injury. FASEB J (2002) 16(12):1630-2. doi:10.1096/fj.02-0187fje

52. Langen RC, Schols AM, Kelders MC, Wouters EF, Janssen-Heininger YM. Inflammatory cytokines inhibit myogenic differentiation through activation of nuclear factor-kappaB. FASEB J (2001) 15(7):1169-80. doi:10.1096/fj.00-0463

53. Langen RC, Van Der Velden JL, Schols AM, Kelders MC, Wouters EF, JanssenHeininger YM. Tumor necrosis factor-alpha inhibits myogenic differentiation through MyoD protein destabilization. FASEB J (2004) 18(2):227-37. doi:10.1096/fj.03-0251com

54. Langen RC, Schols AM, Kelders MC, van der Velden JL, Wouters EF, JanssenHeininger YM. Muscle wasting and impaired muscle regeneration in a murine model of chronic pulmonary inflammation. Am J Respir Cell Mol Biol (2006) 35(6):689-96. doi:10.1165/rcmb.2006-0103OC

55. Tidball JG, Wehling-Henricks M. Macrophages promote muscle membrane repair and muscle fibre growth and regeneration during modified muscle loading in mice in vivo. J Physiol (2007) 578(Pt 1):327-36. doi:10.1113/jphysiol. 2006.118265

56. Singer AJ, Clark RA. Cutaneous wound healing. N Engl J Med (1999) 341(10):738-46. doi:10.1056/NEJM199909023411006

57. Gurtner GC, Werner S, Barrandon Y, Longaker MT. Wound repair and regeneration. Nature (2008) 453(7193):314-21. doi:10.1038/nature07039

58. Huebener P, Schwabe RF. Regulation of wound healing and organ fibrosis by toll-like receptors. Biochim Biophys Acta (2013) 1832(7):1005-17. doi:10.1016/j.bbadis.2012.11.017

59. Galli SJ, Borregaard N, Wynn TA. Phenotypic and functional plasticity of cells of innate immunity: macrophages, mast cells and neutrophils. Nat Immunol (2011) 12(11):1035-44. doi:10.1038/ni.2109

60. Sindrilaru A, Scharffetter-Kochanek K. Disclosure of the culprits: macrophages-versatile regulators of wound healing. Adv Wound Care (New Rochelle) (2013) 2(7):357-68. doi:10.1089/wound.2012.0407

61. Hinz B, Phan SH, Thannickal VJ, Prunotto M, Desmouliere A, Varga J, et al. Recent developments in myofibroblast biology: paradigms for connective tissue remodeling. Am J Pathol (2012) 180(4):1340-55. doi:10.1016/j.ajpath.2012. 02.004

62. Stout RD. Editorial: macrophage functional phenotypes: no alternatives in dermal wound healing? J Leukoc Biol (2010) 87(1):19-21. doi:10.1189/jlb.0509311

63. Lucas T, Waisman A, Ranjan R, Roes J, Krieg T, Muller W, et al. Differential roles of macrophages in diverse phases of skin repair. J Immunol (2010) 184(7):3964-77. doi:10.4049/jimmunol.0903356

64. Brancato SK, Albina JE. Wound macrophages as key regulators of repair: origin, phenotype, and function. Am J Pathol (2011) 178(1):19-25. doi:10.1016/ j.ajpath.2010.08.003

65. Sindrilaru A, Peters T, Wieschalka S, Baican C, Baican A, Peter H, et al. An unrestrained proinflammatory M1 macrophage population induced by iron impairs wound healing in humans and mice. J Clin Invest (2011) 121(3):985-97. doi:10.1172/JCI44490
66. Mirza R, DiPietro LA, Koh TJ. Selective and specific macrophage ablation is detrimental to wound healing in mice. Am J Pathol (2009) 175(6):2454-62. doi:10.2353/ajpath.2009.090248

67. Mirza R, Koh TJ. Dysregulation of monocyte/macrophage phenotype in wounds of diabetic mice. Cytokine (2011) 56(2):256-64. doi:10.1016/j.cyto. 2011.06.016

68. Khanna S, Biswas S, Shang Y, Collard E, Azad A, Kauh C, et al. Macrophage dysfunction impairs resolution of inflammation in the wounds of diabetic mice. PLoS One (2010) 5(3):e9539. doi:10.1371/journal.pone.0009539

69. Davalos D, Grutzendler J, Yang G, Kim JV, Zuo Y, Jung S, et al. ATP mediates rapid microglial response to local brain injury in vivo. Nat Neurosci (2005) 8(6):752-8. doi:10.1038/nn1472

70. Hines DJ, Hines RM, Mulligan SJ, Macvicar BA. Microglia processes block the spread of damage in the brain and require functional chloride channels. Glia (2009) 57(15):1610-8. doi:10.1002/glia.20874

71. Pineau I, Lacroix S. Proinflammatory cytokine synthesis in the injured mouse spinal cord: multiphasic expression pattern and identification of the cell types involved. J Comp Neurol (2007) 500(2):267-85. doi:10.1002/cne. 21149

72. Yang L, Blumbergs PC, Jones NR, Manavis J, Sarvestani GT, Ghabriel MN. Early expression and cellular localization of proinflammatory cytokines interleukinlbeta, interleukin-6, and tumor necrosis factor-alpha in human traumatic spinal cord injury. Spine (2004) 29(9):966-71. doi:10.1097/00007632 200405010-00004

73. Yang L, Jones NR, Blumbergs PC, Van Den Heuvel C, Moore EJ, Manavis J, et al. Severity-dependent expression of pro-inflammatory cytokines in traumatic spinal cord injury in the rat. J Clin Neurosci (2005) 12(3):276-84. doi:10.1016/j.jocn.2004.06.011

74. Schwartz M. "Tissue-repairing” blood-derived macrophages are essential for healing of the injured spinal cord: from skin-activated macrophages to infiltrating blood-derived cells? Brain Behav Immun (2010) 24(7):1054-7. doi:10.1016/j.bbi.2010.01.010

75. Shechter R, London A, Varol C, Raposo C, Cusimano M, Yovel G, et al. Infiltrating blood-derived macrophages are vital cells playing an antiinflammatory role in recovery from spinal cord injury in mice. PLoS Med (2009) 6(7):e1000113. doi:10.1371/journal.pmed.1000113

76. Miron VE, Boyd A, Zhao JW, Yuen TJ, Ruckh JM, Shadrach JL, et al. M2 microglia and macrophages drive oligodendrocyte differentiation during CNS remyelination. Nat Neurosci (2013) 16(9):1211-8. doi:10.1038/nn.3469

77. Anderson JM. Inflammatory response to implants. ASAIO Trans (1988) 34(2):101-7. doi:10.1097/00002480-198804000-00005

78. Anderson JM, Rodriguez A, Chang DT. Foreign body reaction to biomaterials Semin Immunol (2008) 20(2):86-100. doi:10.1016/j.smim.2007.11.004

79. Dadsetan M, Jones JA, Hiltner A, Anderson JM. Surface chemistry mediates adhesive structure, cytoskeletal organization, and fusion of macrophages. J Biomed Mater Res A (2004) 71(3):439-48. doi:10.1002/jbm.a.30165

80. Henson PM. The immunologic release of constituents from neutrophil leukocytes. II. Mechanisms of release during phagocytosis, and adherence to nonphagocytosable surfaces. J Immunol (1971) 107(6):1547-57.

81. Hernandez-Pando R, Bornstein QL, Aguilar Leon D, Orozco EH, Madrigal VK, Martinez Cordero E. Inflammatory cytokine production by immunological and foreign body multinucleated giant cells. Immunology (2000) 100(3):352-8. doi:10.1046/j.1365-2567.2000.00025.x

82. Kovacs EJ. Fibrogenic cytokines: the role of immune mediators in the development of scar tissue. Immunol Today (1991) 12(1):17-23. doi:10.1016/01675699(91)90107-5

83. Williams GT, Williams WJ. Granulomatous inflammation - a review. J Clin Pathol (1983) 36(7):723-33. doi:10.1136/jcp.36.7.723

84. Ratner BD. The biocompatibility manifesto: biocompatibility for the twentyfirst century. J Cardiovasc Transl Res (2011) 4(5):523-7. doi:10.1007/s12265011-9287-x

85. Williams DF. On the mechanisms of biocompatibility. Biomaterials (2008) 29(20):2941-53. doi:10.1016/j.biomaterials.2008.04.023

86. Brown BN, Badylak SF. Expanded applications, shifting paradigms and an improved understanding of host-biomaterial interactions. Acta Biomater (2013) 9(2):4948-55. doi:10.1016/j.actbio.2012.10.025

87. Badylak SF, Brown BN, Gilbert TW, Daly KA, Huber A, Turner NJ. Biologic scaffolds for constructive tissue remodeling. Biomaterials (2011) 32(1):316-9. doi:10.1016/j.biomaterials.2010.09.018 
88. Brown BN, Badylak SF. Extracellular matrix as an inductive scaffold for functional tissue reconstruction. Transl Res (2014) 163(4):268-85. doi:10.1016/j. trsl.2013.11.003

89. Crapo PM, Gilbert TW, Badylak SF. An overview of tissue and whole organ decellularization processes. Biomaterials (2011) 32(12):3233-43. doi:10.1016/ j.biomaterials.2011.01.057

90. Gilbert TW, Sellaro TL, Badylak SF. Decellularization of tissues and organs. Biomaterials (2006) 27(19):3675-83. doi:10.1016/j.biomaterials.2006.02.014

91. Valentin JE, Badylak JS, McCabe GP, Badylak SF. Extracellular matrix bioscaffolds for orthopaedic applications. A comparative histologic study. J Bone Joint Surg Am (2006) 88(12):2673-86. doi:10.2106/JBJS.E.01008

92. Badylak SF, Valentin JE, Ravindra AK, McCabe GP, Stewart-Akers AM. Macrophage phenotype as a determinant of biologic scaffold remodeling. Tissue Eng Part A (2008) 14(11):1835-42. doi:10.1089/ten.tea.2007.0264

93. Brown BN, Valentin JE, Stewart-Akers AM, McCabe GP, Badylak SF. Macrophage phenotype and remodeling outcomes in response to biologic scaffolds with and without a cellular component. Biomaterials (2009) 30(8):1482-91. doi:10.1016/j.biomaterials.2008.11.040

94. Rafii S, Lyden D. Therapeutic stem and progenitor cell transplantation for organ vascularization and regeneration. Nat Med (2003) 9(6):702-12. doi:10.1038/nm0603-702

95. Urish KL, Vella JB, Okada M, Deasy BM, Tobita K, Keller BB, et al. Antioxidant levels represent a major determinant in the regenerative capacity of muscle stem cells. Mol Biol Cell (2009) 20(1):509-20. doi:10.1091/mbc.E0803-0274

96. Guerette B, Asselin I, Skuk D, Entman M, Tremblay JP. Control of inflammatory damage by anti-LFA-1: increase success of myoblast transplantation. Cell Transplant (1997) 6(2):101-7. doi:10.1016/S0963-6897(96)00230-8

97. Huard J, Acsadi G, Jani A, Massie B, Karpati G. Gene transfer into skeletal muscles by isogenic myoblasts. Hum Gene Ther (1994) 5(8):949-58. doi:10.1089/hum.1994.5.8-949

98. Fan Y, Maley M, Beilharz M, Grounds M. Rapid death of injected myoblasts in myoblast transfer therapy. Muscle Nerve (1996) 19(7):853-60. doi:10.1002/ (SICI) 1097-4598(199607) 19:7<853::AID-MUS7>3.0.CO;2-8

99. Camargo FD, Chambers SM, Drew E, McNagny KM, Goodell MA. Hematopoietic stem cells do not engraft with absolute efficiencies. Blood (2006) 107(2):501-7. doi:10.1182/blood-2005-02-0655

100. Glimm H, Oh IH, Eaves CJ. Human hematopoietic stem cells stimulated to proliferate in vitro lose engraftment potential during their $\mathrm{S} / \mathrm{G}(2) / \mathrm{M}$ transit and do not reenter G(0). Blood (2000) 96(13):4185-93.

101. Sicari BM, Dearth CL, Badylak SF. Tissue engineering and regenerative medicine approaches to enhance the functional response to skeletal muscle injury. Anat Rec (2014) 297(1):51-64. doi:10.1002/ar.22794

102. Gnecchi M, He H, Liang OD, Melo LG, Morello F, Mu H, et al. Paracrine action accounts for marked protection of ischemic heart by Akt-modified mesenchymal stem cells. Nat Med (2005) 11(4):367-8. doi:10.1038/nm0405-367

103. Murry CE, Reinecke H, Pabon LM. Regeneration gaps: observations on stem cells and cardiac repair. J Am Coll Cardiol (2006) 47(9):1777-85. doi:10.1016/ j.jacc.2006.02.002

104. Gharaibeh B, Lavasani M, Cummins JH, Huard J. Terminal differentiation is not a major determinant for the success of stem cell therapy - cross-talk between muscle-derived stem cells and host cells. Stem Cell Res Ther (2011) 2(4):31. doi:10.1186/scrt72

105. Perez-Ilzarbe M, Agbulut O, Pelacho B, Ciorba C, San Jose-Eneriz E, Desnos $\mathrm{M}$, et al. Characterization of the paracrine effects of human skeletal myoblasts transplanted in infarcted myocardium. Eur J Heart Fail (2008) 10(11):1065-72. doi:10.1016/j.ejheart.2008.08.002

106. Gnecchi M, Zhang Z, Ni A, Dzau VJ. Paracrine mechanisms in adult stem cell signaling and therapy. Circ Res (2008) 103(11):1204-19. doi:10.1161/ CIRCRESAHA.108.176826

107. Arthur A, Zannettino A, Gronthos S. The therapeutic applications of multipotential mesenchymal/stromal stem cells in skeletal tissue repair. J Cell Physiol (2009) 218(2):237-45. doi:10.1002/jcp.21592

108. Le Blanc K, Ringden O. Immunomodulation by mesenchymal stem cells and clinical experience. J Intern Med (2007) 262(5):509-25. doi:10.1111/j.13652796.2007.01844.x

109. Le Blanc K. Mesenchymal stromal cells: tissue repair and immune modulation. Cytotherapy (2006) 8(6):559-61. doi:10.1080/14653240601045399
110. Le Blanc K. Immunomodulatory effects of fetal and adult mesenchymal stem cells. Cytotherapy (2003) 5(6):485-9. doi:10.1080/14653240310003611

111. Kim J, Hematti P. Mesenchymal stem cell-educated macrophages: a novel type of alternatively activated macrophages. Exp Hematol (2009) 37(12):1445-53. doi:10.1016/j.exphem.2009.09.004

112. Eggenhofer E, Hoogduijn MJ. Mesenchymal stem cell-educated macrophages. Trans Res (2012) 1(1):12. doi:10.1186/2047-1440-1-12

113. Gao S, Mao F, Zhang B, Zhang L, Zhang X, Wang M, et al. Mouse bone marrow-derived mesenchymal stem cells induce macrophage M2 polarization through the nuclear factor-kappaB and signal transducer and activator of transcription 3 pathways. Exp Biol Med (2014) 239(3):366-75. doi:10.1177/1535370213518169

114. Nakajima H, Uchida K, Guerrero AR, Watanabe S, Sugita D, Takeura N, et al. Transplantation of mesenchymal stem cells promotes an alternative pathway of macrophage activation and functional recovery after spinal cord injury. J Neurotrauma (2012) 29(8):1614-25. doi:10.1089/neu.2011.2109

115. Walker PA, Bedi SS, Shah SK, Jimenez F, Xue H, Hamilton JA, et al. Intravenous multipotent adult progenitor cell therapy after traumatic brain injury: modulation of the resident microglia population. J Neuroinflammation (2012) 9:228. doi:10.1186/1742-2094-9-228

116. Dayan V, Yannarelli G, Billia F, Filomeno P, Wang XH, Davies JE, et al. Mesenchymal stromal cells mediate a switch to alternatively activated monocytes/macrophages after acute myocardial infarction. Basic Res Cardiol (2011) 106(6):1299-310. doi:10.1007/s00395-011-0221-9

117. Yannarelli G, Dayan V, Pacienza N, Lee CJ, Medin J, Keating A. Human umbilical cord perivascular cells exhibit enhanced cardiomyocyte reprogramming and cardiac function after experimental acute myocardial infarction. Cell Transplant (2013) 22(9):1651-66. doi:10.3727/096368912X657675

118. Adutler-Lieber S, Ben-Mordechai T, Naftali-Shani N, Asher E, Loberman D, Raanani E, et al. Human macrophage regulation via interaction with cardiac adipose tissue-derived mesenchymal stromal cells. J Cardiovasc Pharmacol Ther (2013) 18(1):78-86. doi:10.1177/1074248412453875

119. Wise AF, Williams TM, Kiewiet MB, Payne NL, Siatskas C, Samuel CS, et al. Human mesenchymal stem cells alter macrophage phenotype and promote regeneration via homing to the kidney following ischemia-reperfusion injury. Am J Physiol Renal Physiol (2014) 306(10):F1222-35. doi:10.1152/ajprenal. 00675.2013

120. Geng Y, Zhang L, Fu B, Zhang J, Hong Q, Hu J, et al. Mesenchymal stem cells ameliorate rhabdomyolysis-induced acute kidney injury via the activation of M2 macrophages. Stem Cell Res Ther (2014) 5(3):80. doi:10.1186/ scrt469

121. Song X, Xie S, Lu K, Wang C. Mesenchymal stem cells alleviate experimental asthma by inducing polarization of alveolar macrophages. Inflammation (2014). doi:10.1007/s10753-014-9954-6

122. Brodbeck WG, Anderson JM. Giant cell formation and function. Curr Opin Hematol (2009) 16(1):53-7. doi:10.1097/MOH.0b013e32831ac52e

123. Wolf MT, Dearth CL, Ranallo CA, LoPresti ST, Carey LE, Daly KA, et al. Macrophage polarization in response to ECM coated polypropylene mesh. Biomaterials (2014) 35(25):6838-49. doi:10.1016/j.biomaterials.2014.04.115

124. Faulk DM, Londono R, Wolf MT, Ranallo CA, Carruthers CA, Wildemann JD, et al. ECM hydrogel coating mitigates the chronic inflammatory response to polypropylene mesh. Biomaterials (2014) 35(30):8585-95. doi:10.1016/j. biomaterials.2014.06.057

125. Wolf MT, Vodovotz Y, Tottey S, Brown BN, Badylak SF. Predicting in vivo responses to biomaterials via combined in vitro and in silico analysis. Tissue Eng Part C Methods (2014). doi:10.1089/ten.tec.2014.0167

126. Saino E, Focarete ML, Gualandi C, Emanuele E, Cornaglia AI, Imbriani M, et al. Effect of electrospun fiber diameter and alignment on macrophage activation and secretion of proinflammatory cytokines and chemokines. Biomacromolecules (2011) 12(5):1900-11. doi:10.1021/bm200248h

127. Garg K, Pullen NA, Oskeritzian CA, Ryan JJ, Bowlin GL. Macrophage functional polarization $(\mathrm{M} 1 / \mathrm{M} 2)$ in response to varying fiber and pore dimensions of electrospun scaffolds. Biomaterials (2013) 34(18):4439-51. doi:10.1016/j. biomaterials.2013.02.065

128. Sussman EM, Halpin MC, Muster J, Moon RT, Ratner BD. Porous implants modulate healing and induce shifts in local macrophage polarization in the foreign body reaction. Ann Biomed Eng (2014) 42(7):1508-16. doi:10.1007/ s10439-013-0933-0 
129. Bota PC, Collie AM, Puolakkainen P, Vernon RB, Sage EH, Ratner BD, et al. Biomaterial topography alters healing in vivo and monocyte/macrophage activation in vitro. J Biomed Mater Res A (2010) 95(2):649-57. doi:10.1002/jbm.a. 32893

130. Fukano Y, Usui ML, Underwood RA, Isenhath S, Marshall AJ, Hauch KD, et al. Epidermal and dermal integration into sphere-templated porous poly (2hydroxyethyl methacrylate) implants in mice. J Biomed Mater Res A (2010) 94(4):1172-86. doi:10.1002/jbm.a.32798

131. Madden LR, Mortisen DJ, Sussman EM, Dupras SK, Fugate JA, Cuy JL, et al. Proangiogenic scaffolds as functional templates for cardiac tissue engineering. Proc Natl Acad Sci U S A (2010) 107(34):15211-6. doi:10.1073/pnas. 1006442107

132. Mokarram N, Merchant A, Mukhatyar V, Patel G, Bellamkonda RV. Effect of modulating macrophage phenotype on peripheral nerve repair. Biomaterials (2012) 33(34):8793-801. doi:10.1016/j.biomaterials.2012.08.050

133. Badylak SF. Regenerative medicine and developmental biology: the role of the extracellular matrix. Anat Rec B New Anat (2005) 287(1):36-41. doi:10.1002/ ar.b.20081

134. Badylak SF. The extracellular matrix as a biologic scaffold material. Biomaterials (2007) 28(25):3587-93. doi:10.1016/j.biomaterials.2007.04.043

135. Badylak SF. Decellularized allogeneic and xenogeneic tissue as a bioscaffold for regenerative medicine: factors that influence the host response. Ann Biomed Eng (2014) 42(7):1517-27. doi:10.1007/s10439-013-0963-7

136. Badylak SF, Vorp DA, Spievack AR, Simmons-Byrd A, Hanke J, Freytes DO, et al. Esophageal reconstruction with ECM and muscle tissue in a dog model. J Surg Res (2005) 128(1):87-97. doi:10.1016/j.jss.2005.03.002

137. Sicari BM, Rubin JP, Dearth CL, Wolf MT, Ambrosio F, Boninger M, et al. An acellular biologic scaffold promotes skeletal muscle formation in mice and humans with volumetric muscle loss. Sci Transl Med (2014) 6(234):234ra58. doi:10.1126/scitranslmed.3008085

138. Gilbert TW. Strategies for tissue and organ decellularization. J Cell Biochem (2012) 113(7):2217-22. doi:10.1002/jcb.24130

139. Keane TJ, Londono R, Turner NJ, Badylak SF. Consequences of ineffective decellularization of biologic scaffolds on the host response. Biomaterials (2012) 33(6):1771-81. doi:10.1016/j.biomaterials.2011.10.054

140. Freytes DO, Martin J, Velankar SS, Lee AS, Badylak SF. Preparation and rheological characterization of a gel form of the porcine urinary bladder matrix. Biomaterials (2008) 29(11):1630-7. doi:10.1016/j.biomaterials.2007.12.014

141. Wolf MT, Daly KA, Brennan-Pierce EP, Johnson SA, Carruthers CA, D'Amore A, et al. A hydrogel derived from decellularized dermal extracellular matrix. Biomaterials (2012) 33(29):7028-38. doi:10.1016/j.biomaterials.2012.06.051
142. Wolf MT, Carruthers CA, Dearth CL, Crapo PM, Huber A, Burnsed OA, et al. Polypropylene surgical mesh coated with extracellular matrix mitigates the host foreign body response. J Biomed Mater Res A (2014) 102A(1):234-46. doi:10.1002/jbm.a.34671

143. Murray PJ, Allen JE, Biswas SK, Fisher EA, Gilroy DW, Goerdt S, et al. Macrophage activation and polarization: nomenclature and experimental guidelines. Immunity (2014) 41(1):14-20. doi:10.1016/j.immuni.2014.06.008

144. Ginhoux F, Lim S, Hoeffel G, Low D, Huber T. Origin and differentiation of microglia. Front Cell Neurosci (2013) 7:45. doi:10.3389/fncel.2013.00045

145. Prinz M, Tay TL, Wolf Y, Jung S. Microglia: unique and common features with other tissue macrophages. Acta Neuropathol (2014) 128(3):319-31. doi:10.1007/s00401-014-1267-1

146. Prinz M, Priller J. Microglia and brain macrophages in the molecular age: from origin to neuropsychiatric disease. Nat Rev Neurosci (2014) 15(5):300-12. doi: $10.1038 / \mathrm{nrn} 3722$

147. Davies LC, Jenkins SJ, Allen JE, Taylor PR. Tissue-resident macrophages. Nat Immunol (2013) 14(10):986-95. doi:10.1038/ni.2705

148. Akira S, Misawa T, Satoh T, Saitoh T. Macrophages control innate inflammation. Diabetes Obes Metab (2013) 15(Suppl 3):10-8. doi:10.1111/dom.12151

149. Mahbub S, Deburghgraeve CR, Kovacs EJ. Advanced age impairs macrophage polarization. J Interferon Cytokine Res (2012) 32(1):18-26. doi:10.1089/jir. 2011.0058

Conflict of Interest Statement: The authors declare that the research was conducted in the absence of any commercial or financial relationships that could be construed as a potential conflict of interest.

Received: 28 August 2014; accepted: 01 October 2014; published online: 04 November 2014.

Citation: Brown BN, Sicari BM and Badylak SF (2014) Rethinking regenerative medicine: a macrophage-centered approach. Front. Immunol. 5:510. doi: 10.3389/fimmu.2014.00510

This article was submitted to Inflammation, a section of the journal Frontiers in Immunology.

Copyright $(2014$ Brown, Sicari and Badylak. This is an open-access article distributed under the terms of the Creative Commons Attribution License (CC BY). The use, distribution or reproduction in other forums is permitted, provided the original author(s) or licensor are credited and that the original publication in this journal is cited, in accordance with accepted academic practice. No use, distribution or reproduction is permitted which does not comply with these terms. 